\title{
Editorial - networks and individuals in international organizations
}

\author{
Barbara Watson Andaya
}

Contributors to this journal have frequently used international organizations as a departure point from which to examine the ways in which global history has been shaped by worldwide interactions. Although these three articles were submitted separately, we have brought them together in a cluster because they share a common theme. From different vantage points, they all focus on the social and professional networks that developed in international organizations, connecting individuals from diverse cultures and often from dissimilar political backgrounds. In different ways, each author demonstrates that personal friendships and shared interests can address a range of problems, and in many cases directly affect the historical trajectories of transnational organizations and movements. However, the articles also reveal the divergences that have imposed constraints on collaboration, undermined cooperative efforts, and given rise to unsettling questions regarding goals and strategies. Some of these critiques can be traced to the fact that international groupings, whether developed by government officials or by private citizens, have been largely dominated by individuals from Europe and the United States. The articles show that differences in outlook and goals can cause strains even within outwardly compatible groups, and among apparently like-minded individuals. Despite the hopes for enhanced global partnerships, networking at all levels has often been overwhelmed or redirected by government policies, as nations themselves jostle for space on the world stage and compete to assert their own priorities.

These issues are all brought to the fore in this cluster. The first article, by Tomoko Akami, focuses on the League of Nations Health Organization (LNHO), whose members sought to improve the administration of public health in Africa and Asia through collaborative projects. The prime movers in these endeavours were representatives of colonial administrations rather than of sovereign nation-states, but they were regarded as 'legitimate units' in intergovernmental meetings, best exemplified in the 1937 Bandung conference on rural hygiene. In comparing activities in Asia and Africa, Akami argues that the LNHO was able to draw on its relationship to the Far Eastern Association of Tropical Medicine, established in 1908, which had already created an Asian precedent for collaboration between representatives from colonial administrations. As the Bandung conference showed, personal networks and 'lateral relationships' among Asia's locally based medical experts provided a strong base for generating international health schemes that were especially applicable to rural populations. Even if the primary concern was governance rather than advocating access to medical treatment as a 
right, the willingness to work across national boundaries, and to include qualified people of any race, was highly significant. At the same time, local medical experts, trained in the colonial system, were themselves confronted with contradictions between the demands of economic development and the needs of disadvantaged communities in their own society.

The second article, by Matthias Schmelzer, moves up in time to examine another interrelated but in this case unlikely network. Established in 1961, the intergovernmental Organisation for Economic Co-operation and Development (OECD) was focused on promoting economic development and global trade. But, as Schmelzer shows, undercurrents of dissent soon surfaced because some OECD scientists were concerned about the global consequences of unrestrained growth, and were disturbed by demonstrations of public alienation, especially the student protests of 1968. The 'Club of Rome' was formed by this dissenting group. In 1972 its computer-based predictions of an imperilled global future, published in The limits to growth, took the thinking world by storm. Through the personal relationships and transnational networks that connected OECD and Club of Rome members, Schmelzer has tracked the flow of influences that linked entrepreneurs, experts, and government officials. Rather than reflecting national interests, members of these networks often acted quite independently of their national governments and even in disagreement with official policies. Simultaneously, the very linkages between private and state actors triggered further debates and disagreements, at times reflecting the nature of academic training, and at others the animosities rooted in political differences. Nearly fifty years later, the issues discussed in the 1970s are still relevant and questions of sustainability remain at the top of the international agenda.

The third article, by Agnieszka Sobocinska, is a comparative study of three volunteer organizations, the Australian Volunteer Graduate Scheme (VGS), the British Voluntary Service Overseas (VSO), and the United States Peace Corps. All emerged from a conviction that the citizens of developed countries had a moral responsibility to assist 'undeveloped' societies. Though the VGS began as a small, student-based initiative, in the 1950s and 1960s its 'volunteering' model found a global audience through individual networking and promotional efforts, as well as support from government agencies. As Sobocinska shows, Australia, Britain, and the United States all believed that young and enthusiastic volunteers could be a means of burnishing national images associated with racism or the colonial past. Given the Afro-Asian interest in non-alignment, marked by the conference at Bandung in 1955 (very different from the 1937 meeting described by Akami), such individuals could also act as their society's surrogates to counter suspicions of Western ambitions. ${ }^{1}$ Nevertheless, even among the best intentioned, it was difficult to separate the goals of 'developmental volunteering' from the notion that developed societies should act as global (and implicitly superior) mentors for 'the rest'. Effective networks may have resulted from the commitment of people rather than governments but, by their very involvement, young volunteers were caught up in neo-colonial systems of competitive national rivalries that 'undeveloped' countries clearly understood and resented.

Finally, following on from the 'Educational networks' cluster in the previous issue of this journal, all three contributors in the current set of articles have been concerned to explain the significance of their findings for global history. Akami reminds us that the focus on national 'vertical' involvement in international organizations in the 1920s and 1930s has often

1 The mood of the Bandung Conference is discussed in Christoph Kalter's contribution to this issue. 
overlooked the role played by colonial governments and their representatives. This 'horizontal' interaction, and the inclusion (albeit limited) of local medical experts, helped foster the lateral cooperation that became a norm of later international organizations. For his part, Schmelzer argues that transnational networks, such as the Club of Rome, can successfully insert their view into the domain, and through this means, rather than by direct political intervention, help bring about changes in governmental attitudes. In generating a still-vigorous challenge to the growth-capitalism agenda, global networking in the 1970s had a significant impact on the shaping of world history. Sobocinska's comparative study shows that, although historians have typically approached the topic of development from a government standpoint, initiatives begun or supported in the domain of civil society can have a major impact. As an agent of 'soft power', however, the volunteering model could not fail to attract the attention of national governments, even as it has remained a disturbing reminder of the imbalance in world economies. Early idealism may have faded, but the Peace Corps now operates in over sixty countries.

At a point when global governance is facing so many pressures, these articles are thus timely. On the one hand, they demonstrate the underlying tensions that are an almost inevitable outcome when governments compete both to protect their national interests and to expand their global reach. On the other, they show what can be accomplished through personal and transnational networking, whether this stems from conversations among Australian and Indonesian students on a ship to India, or a private meeting in the OECD Paris headquarters between a Scottish scientist and an Italian industrialist. In this sense, we are shown that individuals do have a place to play in the amorphous domain of 'global history', and that their engaged action can be influential and meaningful. 